
\title{
is Research Square \\ Factors that influence in cell condensate morphology, dynamics, and oligomerization
}

Ryan Emenecker

Alex Holehouse

Lucia Strader

\section{Video Byte}

Keywords: Cell Communication and Signaling, intrinsically disordered regions, biomolecular condensates, oligomerization, oligomerization domains, quantitative microscopy, plant model, Arabidopsis, number and brightness analysis, fluorescence microscopy, fluorescence recovery after photobleaching

Posted Date: October 13th, 2021

DOl: https://doi.org/10.21203/rs.3.rs-966224/v1

License: (c) (1) This work is licensed under a Creative Commons Attribution 4.0 International License.

Read Full License 


\section{Abstract}

In all kingdoms of life, cells need mechanisms to organize their contents. One way this is can be achieved is with membrane-bound organelles, but cells also form biomolecular condensates, which are concentrated assemblies of cellular components that do not adhere to stoichiometric principles. The proteins driving the formation of these condensates typically contain oligomerization domains and intrinsically disordered regions (IDRs). Our current understanding of the contribution of these regions in living cells is limited, particularly over time and compared to each other. Recent research using quantitative microscopy examined condensates formed by AUXIN RESPONSE FACTOR 19 (ARF19), a transcription factor found in plants. This protein has a large central IDR and an oligomerization domain at the c-terminus. The IDR amino acid sequence influenced the morphology and material properties of ARF19's condensates, but did not influence the distribution of oligomeric species. These results match the growing consensus that IDR composition impacts the physical properties of biomolecular condensates. However, they also suggest that, at least in this system, the IDR composition has a limited role in governing the oligomeric state of the condensates. 